\title{
História, Estado e Educação: uma leitura sobre o Estado brasileiro (1971-2000)1
}

\section{History, state and education: a reading of the Brazilian state (1971-2000)}

\author{
Nadia Gaiofatto Gonçalves*
}

\begin{abstract}
RESUMO
$\mathrm{O}$ artigo apresenta alguns resultados de pesquisa realizada sobre se e como o tema Estado e Educação foi abordado na produção acadêmica brasileira, no período compreendido entre 1971 a 2000. Foram pesquisados cinco Anais de Associações Nacionais de Pós-Graduação e Pesquisa e quinze periódicos, das áreas de Educação, Economia, Administração, História, e Ciências Sociais. Buscou-se compreender as perspectivas das áreas, considerando-se o contexto histórico das décadas em que os trabalhos foram produzidos, e evidenciando seus nexos, contribuições e limitações. Neste artigo, é abordada a caracterização do Estado brasileiro, pelos autores dos trabalhos investigados, em especial quanto a três referências principais, que aparecem ao longo de todo o período: Estado capitalista/reprodutor da ordem social; Estado autoritário/centralizador; e Estado ineficiente/omisso, buscando-se compreendê-las em relação ao contexto histórico.

Palavras-chave: Estado, educação básica, políticas educacionais, produção acadêmica, História da Educação.
\end{abstract}

\begin{abstract}
This article presents the results of the research about how the State and Education topic were dealt with in the Brazilian academic production between 1971 and 2000. We have researched five Proceedings of PostGraduation and National Research Associations and fifteen journals

1 Pesquisa realizada durante o doutorado na Faculdade de Educação da USP (GONÇALVES, 2003). Contou com financiamento parcial da FAPESP.

* Professora do Departamento de Teoria e Prática de Ensino e do Programa de Pós-Graduação em Educação da Universidade Federal do Paraná (UFPR), na Linha de Pesquisa de História e Historiografia da Educação. E-mail: nadia_ggoncalves@ufpr.br.
\end{abstract}


in the areas of Economy, Administration, History, Social Sciences and Education, focusing on four titles in each one of them, in considering the total production of the period. We tried to understand the perspectives of the areas. We have considered the historical context of the decades in which those works were produced, highlighting their contributions and limitations. In this article, we approach the characterization of the Brazilian State by the authors of researched works, especially concerning the three main references that appear throughout the period: the capitalist State/ producer of social order; the authoritarian State/centralizer; and the inefficient State / the absent state. We seek to understand them in their historical context.

Key words: State, primary education, educational policies, academic production, historical context and education.

\section{Introdução: tema, objetivo, procedimentos metodológicos e referencial analítico}

Esta pesquisa teve como objetivo desenvolver uma análise sobre se e como o tema Estado e Educação - referente à educação básica - foi tratado no período compreendido entre 1971 e 2000, em anais e periódicos acadêmicos nacionais. Neste artigo, será abordada a caracterização do Estado brasileiro, pelos autores dos trabalhos investigados ${ }^{2}$.

O tema remete às relações históricas entre o Estado e a Educação no Brasil, mais especificamente ao seu papel e atuação em relação à educação básica. Foi estabelecido o período de 1971 a 2000, a fim de abranger as Leis n. 5.692/71 e n. 9.394/96, fundamentais para a compreensão da educação básica no período ${ }^{3}$.

${ }^{2}$ Não se pretende esgotar o assunto, uma vez que ele está relacionado com outras questões abordadas e identificadas na pesquisa; porém, optou-se por uma delimitação central para o tema e para a investigação realizada, e por tratar das tendências predominantes do material analisado sobre o tema. Nesse caso, as divergências e características específicas de cada área deverão ser discutidas em outro artigo.

${ }^{3}$ Abordar a totalidade da década de 1990 na pesquisa foi considerado relevante, tendo em vista a reconfiguração do papel do Estado na gestão da educação pública, no decorrer de um período histórico de grandes mudanças políticas, econômicas e sociais do país, como o auge e o fim da ditadura militar, a transição política e os questionamentos sobre o papel do Estado, em âmbito internacional e nacional, suscitando estudos, pesquisas e produções acadêmicas. Também pretendeu-se abranger as repercussões e discussões a respeito da Lei de Diretrizes e Bases da Educação Nacional (LDB) de 1996, após sua promulgação, entendendo-se que essa lei, mais do que decorrência do processo de reforma do Estado, faz parte dele. 
Foram investigados vinte periódicos, entre revistas e Anais de Associações Nacionais de diferentes áreas do conhecimento: Anped (Educação), Anpuh (História), Anpad (Administração), Anpec (Economia) e Anpocs (Ciências Sociais $)^{4}$, na totalidade de suas publicações no período. Os quinze periódicos selecionados foram todos localizados: Cadernos de Pesquisa (FCC), Educação e Sociedade (Unicamp), Revista Brasileira de Educação (Anped), Estudos Históricos (FGV - CPDOC), Revista de História (USP), Revista Brasileira de História (Anpuh), Revista de Administração Pública (FGV-RJ), Revista de Administração (USP), Revista de Administração de Empresas (FGV-SP), Revista de Economia Política (CEP-RJ), Economia e Sociedade (Unicamp), Pesquisa e Planejamento Econômico (IPEA), Novos Estudos (Cebrap), Sociedade e Estado (UnB) e Revista Brasileira de Ciências Sociais (Anpocs).

Optou-se por incluir na pesquisa somente os trabalhos dos quais fossem obtidos os textos integrais. Os 202 trabalhos selecionados ${ }^{5}$ foram lidos, resumidos e classificados sob diversos quesitos, entre os quais: publicação, área, ano, instituição de origem do autor, tema e sub-tema, referências ao Estado (papel, funções, atuação, ou ainda o modelo de Estado) e expectativas (demandas em relação à Educação e à atuação do Estado nesse campo).

O principal referencial analítico foi a teoria dos campos, com os conceitos de habitus, campo, capital e poder simbólico, de Pierre Bourdieu (1988, 1989, 1996). O autor enfatiza as limitações de entendimento de uma dada realidade e os determinantes histórico-sociais que a envolvem e que pesam sobre a produção do conhecimento relativo a ela - embora considere que esta limitação configura, mas não determina a ação, sendo, porém, suficiente para criar padrões de comportamento e de interpretação no campo, nesse caso, o acadêmico.

A fim de melhor explicitar as relações entre os conceitos mencionados, Bourdieu compara o funcionamento do campo à organização e desenvolvimento de um determinado jogo, cujas regras não são explícitas mas compreensíveis para os agentes que dele participam, a partir do habitus:

4 Tanto as bibliotecas quanto as Secretarias das Associações pesquisadas não dispunham, em seus acervos, dos registros completos dos eventos que realizaram, com exceção da Anpec.

5 Da área de Educação foram 158, 21 das Ciências Sociais, 15 da Administração, 5 da Economia e 3 da História. 
[...] não se deve colocar o problema em termos de espontaneidade e coação, liberdade e necessidade, indivíduo e social. O habitus como sentido do jogo é jogo social incorporado, transformado em natureza. Nada é simultaneamente mais livre e mais coagido do que a ação do bom jogador. [...] O habitus como social inscrito no corpo, no indivíduo biológico, permite produzir a infinidade de atos de jogo que estão inscritos no jogo em estado de possibilidades e de exigências objetivas; as coações e as exigências do jogo, ainda que não estejam reunidas num código de regras, impõem-se àqueles que, por terem o sentido do jogo, isto é, o senso da necessidade imanente do jogo, estão preparados para percebêlas e realizá-las. [...] E as regularidades que se podem observar, graças à estatística, são o produto agregado de ações individuais orientadas pelas mesmas coações objetivas (as necessidades inscritas na estrutura do jogo ou parcialmente objetivadas em regras) ou incorporadas (o sentido do jogo, ele próprio distribuído de modo desigual, porque em toda parte, em todos os grupos, existem graus de excelência). (1988, p. 82-83)

A partir da noção de representação, bastante próxima à de habitus, Chartier (1988) aborda a questão das leituras ou dos entendimentos possíveis, ou as diferentes formas que uma realidade é dada a ler. Segundo ele, as percepções dos sujeitos sociais não são neutras, dependendo do contexto em que foram elaboradas, e derivando delas as suas práticas. Por sua vez, Braudel (1978) considera que "as ciências humanas se interessam todas por uma mesma e única paisagem: a das ações passadas, presentes e futuras do homem", e representam observatórios, com suas "vistas particulares, seus esboços perspectivos diferentes". (p.80)

Com base nesse referencial, assume-se aqui que diferentes áreas de conhecimento são campos distintos, com culturas e olhares específicos sobre a realidade. As perspectivas dessas áreas acadêmicas se reportariam às posições que cada uma ocupa em um campo mais amplo, da qual todas fazem parte, o acadêmico; logo deveria haver consensos, estabelecidos, em grande parte, pelo contexto histórico. Dessa forma, as mudanças nos padrões de regulação do Estado, no período analisado, teriam agido como condicionantes para os rumos da produção acadêmica, embora pudesse haver alguma distância temporal entre essas alterações, a ação do Estado e a realização de estudos sobre elas. 


\section{O Estado brasileiro e a Educação, segundo a produção acadêmica analisada}

Nas três décadas aqui abordadas, o Brasil passou por profundas transformações políticas e econômicas ${ }^{6}$. As políticas públicas sociais - entre as quais a Educação - sofreram alterações em suas ênfases e na forma de atuação do Estado. O Quadro 1 traz uma síntese do tratamento do tema, nos trabalhos analisados.

QUADRO 1 - PRINCIPAIS TEMAS, REFERÊNCIAS AO ESTADO E EXPECTATIVAS SOBRE A RELAÇÃO ESTADO E EDUCAÇÃO, PRESENTES NA PRODUÇÃO ACADÊMICA (1971-2000)

\begin{tabular}{|c|c|c|c|}
\hline PERÍODO & TEMAS & $\begin{array}{l}\text { REFERÊNCIAS AO } \\
\text { ESTADO }\end{array}$ & EXPECTATIVAS \\
\hline 1971-1980 & $\begin{array}{l}\text { - Função e papel da } \\
\text { Educação/escola (8) }\end{array}$ & $\begin{array}{l}\text { - Estado capitalista/ } \\
\text { reprodutor da ordem } \\
\text { social (10) }\end{array}$ & $\begin{array}{l}\text { - Revisão do papel do } \\
\text { ensino e da função da } \\
\text { escola (7) }\end{array}$ \\
\hline \multirow{3}{*}{20 trabalhos } & - Implementação de & $\begin{array}{l}\text { - Estado autoritário/ } \\
\text { centralizador (4) }\end{array}$ & • Democratização (7) \\
\hline & sistemas educacionais (7) & $\begin{array}{l}\text { - Estado ineficiente/ } \\
\text { omisso (3) }\end{array}$ & $\begin{array}{c}\text { - Educação e combate às } \\
\text { desigualdades (6) }\end{array}$ \\
\hline & $\begin{array}{l}\text { - Implementação de políti- } \\
\text { cas e gestão de sistemas } \\
\text { educacionais (23) }\end{array}$ & $\begin{array}{l}\text { - Estado capitalista/ } \\
\text { reprodutor da ordem } \\
\text { social (25) }\end{array}$ & $\begin{array}{l}\text { - Revisão do papel do } \\
\text { ensino e da função da } \\
\text { escola (21) }\end{array}$ \\
\hline \multirow[t]{2}{*}{ 1981-1990 } & $\begin{array}{l}\text { - Função e papel da } \\
\text { Educação/escola (15) }\end{array}$ & $\begin{array}{l}\text { - Estado ineficiente/ } \\
\text { omisso (19) }\end{array}$ & $\begin{array}{l}\text { - Gestão democrática / } \\
\text { mobilização da sociedade } \\
\text { civil (16) }\end{array}$ \\
\hline & $\begin{array}{l}\text { - Normas e documentos } \\
\text { oficiais (11) }\end{array}$ & $\begin{array}{r}\text { - Estado autoritário/ } \\
\text { centralizador (12) }\end{array}$ & $\begin{array}{l}\text { - Comprometimento do } \\
\text { Estado (15) }\end{array}$ \\
\hline 63 trabalhos & & $\begin{array}{l}\text { - Discurso oficial/ } \\
\text { legislação x prática (11) }\end{array}$ & $\begin{array}{l}\text { - Redefinição/vinculação } \\
\text { orçamentária e prestação } \\
\text { de contas (13) }\end{array}$ \\
\hline
\end{tabular}

${ }^{6}$ Essas mudanças não são exclusivas do Brasil, no período, e podem ser observadas em outros países da América Latina. 
QUADRO 1 - PRINCIPAIS TEMAS, REFERÊNCIAS AO ESTADO E EXPECTATIVAS SOBRE A RELAÇÃO ESTADO E EDUCAÇÃO, PRESENTES NA PRODUÇÃO ACADÊMICA (1971-2000)

\begin{tabular}{|c|c|c|c|}
\hline PERÍODO & TEMAS & $\begin{array}{l}\text { REFERÊNCIAS AO } \\
\text { ESTADO }\end{array}$ & EXPECTATIVAS \\
\hline \multirow{2}{*}{ 1991-2000 } & $\begin{array}{l}\text { - Implementação de políti- } \\
\text { cas e gestão de sistemas } \\
\text { educacionais }(50)\end{array}$ & $\begin{array}{l}\text { - Estado neoliberal/ } \\
\text { Estado mínimo (33) }\end{array}$ & $\begin{array}{l}\text { - Gestão democrática/ } \\
\text { mobilização da } \\
\text { sociedade civil (47) }\end{array}$ \\
\hline & $\begin{array}{l}\text { - Função e papel da Edu- } \\
\text { cação/ escola (13) }\end{array}$ & $\begin{array}{l}\text { - Estado ineficiente/ } \\
\text { omisso (23) }\end{array}$ & • Democratização (25) \\
\hline \multirow[t]{5}{*}{119 trabalhos } & $\begin{array}{l}\text { - Normas e documentos } \\
\text { oficiais (13) }\end{array}$ & $\begin{array}{l}\text { - Estado autoritário/ } \\
\text { centralizador (20) }\end{array}$ & $\begin{array}{l}\text { - Descentralização com } \\
\text { critérios democráticos e } \\
\text { recursos financeiros (24) }\end{array}$ \\
\hline & $\begin{array}{l}\text { - Papel do Estado e } \\
\text { Educação (12) }\end{array}$ & $\begin{array}{l}\text { - Tendência à descentrali- } \\
\text { zação (19) }\end{array}$ & $\begin{array}{l}\text { - Revisão do papel do } \\
\text { ensino e da função da } \\
\text { escola (24) }\end{array}$ \\
\hline & & $\begin{array}{l}\text { - Crise e reforma do } \\
\text { Estado (16) }\end{array}$ & \\
\hline & & & $\begin{array}{l}\text { - Educação e combate às } \\
\text { desigualdades (21) }\end{array}$ \\
\hline & & $\begin{array}{l}\text { - Estado capitalista/ } \\
\text { reprodutor da ordem } \\
\text { social (13) }\end{array}$ & $\begin{array}{l}\text { - Qualidade do ensino } \\
\text { (19) }\end{array}$ \\
\hline
\end{tabular}

Dois temas são centrais, durante as três décadas: função da Educação/ escola e Implementação de políticas e gestão de sistemas educacionais. O que muda é a discussão deles, ao longo do tempo, o que pode ser observado nas referências ao Estado e nas expectativas a ele colocadas. Obviamente, tais perspectivas derivam de referenciais teóricos, porém não foi objetivo desta pesquisa classificá-los mas apenas identificar sua manifestação em relação ao tema ${ }^{7}$. Quanto às referências ao Estado, foco central deste artigo, três são recorrentes em todo o período: Estado capitalista/reprodutor da ordem social, Estado autoritário/ centralizador e Estado ineficiente/omisso.

${ }^{7}$ A opção por não avaliar referenciais teóricos deveu-se a três razões principais: 1) pressuporia bom domínio dos referenciais correntes na Educação, bem como nas demais áreas analisadas; 2) exigiria averiguar a coerência entre o anúncio do referencial, pelo pesquisador, sua pertinência e sua efetiva utilização no texto; 3) em caso de haver incoerência, mau uso, indefinição ou mesmo tentativa de utilização de referenciais incompatíveis, seria preciso uma discussão específica. Entende-se que, embora essa análise seja muito pertinente, nesse caso o problema e o objetivo da pesquisa seriam outros, necessitando de uma investigação própria. 
É interessante notar que nas duas primeiras referências há críticas às deficiências de atuação do Estado, atribuídas a uma intencionalidade dos grupos que o constituem. Na última, há em geral um tratamento mais enfático à questão da desorganização, mau uso ou incompetência administrativa, e não tanto à utilização proposital da educação visando à dominação ideológica e à manutenção da ordem social. Somente nos anos de 1990 ocorre a inserção mais forte de outras características a ele atribuídas, como neoliberal/mínimo, tendência à descentralização, e sua crise e reforma. As expectativas são decorrentes e inter-relacionadas às referências, embora não apresentem padrão tão homogêneo quanto aos temas e críticas ao Estado, nas três décadas.

No caso das críticas ao Estado capitalista ${ }^{8}$, os trechos abaixo as ilustram, ao longo do período:

[...] Esta política [educacional] se insere numa política mais ampla de "educação para o desenvolvimento". O propósito central é a modernização e racionalização das instituições que complementam o sistema de produção. Parte-se do suposto de que o grau de desenvolvimento da economia doméstica está condicionado pela falta de eficiência ou à não distribuição racional dos recursos escassos para fins mais produtivos. A solução é posta no aperfeiçoamento e modernização do imperfeito e anacrônico sistema administrativo. [...] O próprio sistema escolar é responsabilizado pelos problemas crônicos que o afetam, por estar irracionalmente administrado. A dimensão política deste quadro clínico está em que dando ênfase à irracionalidade administrativa do sistema, desvia-se, consciente ou inconscientemente, a atenção dos fatores estruturais, verdadeiros responsáveis dos fracassos da escola. Oculta-se que a organização da produção, a divisão técnico-social do trabalho, a distribuição da riqueza e do poder em uma sociedade são fatores condicionantes da distribuição dos recursos educacionais, da quantidade, qualidade e nível de educação que pode ser atingido em cada grupo social. (ARROYO, 1979, p. 36-38)

O tema desta comunicação - Industrialização e Educação - significa, para sermos mais precisos, analisar a educação em um contexto da expansão do modo capitalista de produção em nosso país. Podem ser destacados dois aspectos nesse tema. Um deles é a expropriação do conhecimento dos operários, que se processou com o desenvolvimento do capitalismo e que aqui no Brasil já chega depurado. Outro aspecto é a metamorfose sofrida pelo papel da educação nesta última fase do processo de industrialização no Brasil. [...] tal desprestígio da escolarização está mais ligado à fragilidade

${ }^{8}$ Embora as referências ao Estado sejam aqui apresentadas separadamente, deve-se lembrar que essa organização foi escolhida para fins didáticos, uma vez que a compreensão assumida é de que necessariamente estão inter-relacionadas, como poderá ser observado nos próprios trechos escolhidos para ilustrá-las. 
política do povo, e à sua contrapartida, a força repressiva do Estado, do que à ausência de recursos oficiais para serem aplicados ao setor. (GANDINI, 1980, p. 135)

Martins (1990) analisa a "política educacional no sistema capitalista" (p.61) e discute como o direito à Educação passou a ser associado à intervenção do Estado na sociedade e também na economia. Nesse caso, o Estado deve assegurar bens e serviços mínimos à população, entre os quais a Educação. Para a autora,

[...]o direito a ela não está vinculado necessariamente a um processo de democracia política [...] [mas] à necessidade de um mínimo de instrução para os trabalhadores tomarem parte do processo produtivo. A extensão da educação a todos, então, é também uma necessidade econômica, uma necessidade do processo produtivo. (MARTINS, 1990, p.63).

Nos anos de 1990, a maior ênfase na caracterização do Estado como neoliberal, simultânea ao seu entendimento como capitalista/reprodutor da ordem social, pode ser observada na citação abaixo, que ilustra o pensamento predominante nos trabalhos, qual seja, de que capitalismo e neoliberalismo estão associados:

Pesquisamos as características peculiares a este período histórico, já que inúmeras têm sido as transformações na produção da vida material objetiva e subjetiva nesta fase particular do capitalismo, em função das mudanças que estão ocorrendo na esfera da produção, do mercado e do Estado. Esses são processos distintos, mas que fazem parte de um mesmo movimento histórico, em que o capitalismo, na tentativa de superar sua crise, estabeleceu como estratégias principais o neoliberalismo, a globalização e a reestruturação produtiva. [...] O conceito de Estado que trabalhamos nesta pesquisa é o Estado histórico, concreto, de classe, e, nesse sentido, o Estado máximo para o capital, já que, no processo de correlação de forças em curso, é o capital que detém a hegemonia. (PERONI, 2000, p. 1) 
O perfil neoliberal do Estado, nos trabalhos, é abordado principalmente na forma de denúncias dos problemas sociais e de exclusão que ele traz, e do processo de desresponsabilização estatal em relação à Educação:

O trabalho procura analisar as implicações do debate atual sobre a qualidade do ensino, cujos pressupostos baseiam-se nos fundamentos do neoliberalismo, articulados aos condicionamentos impostos pelo novo reordenamento mundial. Destacando elementos deste reordenamento e das propostas neoliberais para a educação, tenta demonstrar sua impropriedade e seus riscos quando referenciados à realidade brasileira. (AZEVEDO, 1994, p. 449)

Permeando essa compreensão de Estado, sua crise e reforma são também temas de discussão. Nesse sentido, são vistas como característica central do processo de reforma, inerente ao Estado neoliberal e sua desresponsabilização perante a Educação. Porém, essa desresponsabilização não é identificada somente nos anos de 1990; mesmo sob outra denominação, ela aparecia nas discussões sobre o tema, por exemplo, quando os autores se referiam à ineficiência, à omissão ou ao descompromisso estatal em relação à Educação. Essas atitudes atribuídas ao Estado variam quanto à compreensão da intencionalidade: ora são consideradas absolutamente intencionais, ora resultado de incompetência ou de falta de planejamento.

Para respondermos a essas questões [sobre o financiamento da Educação no Brasil], utilizaremos respostas simplistas: - não existem recursos financeiros adequados; o pouco que existe ainda é mal aplicado; e as condições atuais dificultam a obtenção de novas fontes de recursos financeiros. (MELCHIOR, 1978, p. 5)

Este é um diagnóstico recorrente. Por exemplo, a retomada da constatação acima citada: “[...] nosso desempenho escolar é extremamente baixo. O que esses dados mostram é que, no Brasil, gastam-se mal e de forma errada os recursos na área educacional" (RIBEIRO, 1993, p. 75). Outros trechos ilustram os entendimentos a respeito da ineficiência e omissão estatal, atribuindo-as a distintas razões: 
Não é novidade que a Lei no 5.692, de 1971, é completamente omissa, não colocando a obrigatoriedade de nenhum poder municipal, estadual ou federal em relação à pré-escola. Isso acarreta uma dúvida legal de quem teria essa competência, que verbas é que deveriam estar provendo o atendimento. (CAMPOS et al., 1981, p. 37)

[...] todos os esforços dos governos federal, estadual e municipal objetivando a expansão e melhoria do ensino têm encontrado obstáculos representados pelas estruturas administrativas obsoletas existentes em todos os níveis de governo. (MARCELINO, 1981, p. 139)

O descompromisso governamental fica exposto em toda a sua amplitude quando se observa que na proposta de Orçamento da União para 1996, a educação sofreu uma redução de $29,5 \%$ em relação ao Orçamento de 1994, demonstrando que os recursos para o setor ficaram menores do que os destinados à área militar e que a educação, de fato, não é prioridade. (MINTO et al., 1996, p. 561)

Finalmente, a terceira referência mais atribuída ao Estado, nas três décadas: centralizador e autoritário. Porém, deve-se ressaltar as distintas conotações que esses termos vão adquirindo, ao longo do período: em sua primeira metade, referem-se ao controle e determinações próprios do regime militar e da tecnoburocracia então estabelecidas; e principalmente a partir do final da década de 1980, ao controle de recursos e do processo de avaliação, simultaneamente à desconcentração da responsabilidade estatal.

Melchior (1978, p.8), analisando as causas do decréscimo de recursos que deveriam ser aplicados em Educação, indica como uma delas "a ascendência aos postos de decisão política dos tecnoburocratas, situação típica de regimes autoritários, com orientação predominantemente econômica". Outras citações abrangem perspectivas diversas sobre o tema:

Os que estão mais longe [dos centros de poder] são menos capazes de serem ouvidos e de se fazerem presentes nos momentos em que a máquina burocrática toma suas decisões. Não se trata de um mecanismo político premeditado e de cunho conspiratório, mas de uma soma de inúmeras pequenas decisões cujas conseqüências agregadas produzem as situações que conhecemos. Em um estudo de caso que examinamos, uma mesma 
região era atendida por 27 instituições educacionais diferentes. Cada uma delas é sensível a pedidos, requisições, contatos formais e informais, pressões de grandes e pequenos, clientelismo e nepotismo de diferentes matizes. É o "ativismo" burocrático e político que em boa medida vai determinar quem recebe o quê. Quem mais pede, mais recebe. Nessas situações de multiplicação burocrática, o pedido e o contato acabam por ser os mais fortes indicadores de demanda. Recebe, então, quem sabe, quem está perto do poder, quem se organiza, e não necessariamente quem precisa. (CASTRO et al., 1980, p.168)

[...] o Estado tenta imprimir uma roupagem modernizante à sua política autoritária e centralizadora ainda em curso, procurando legitimar as propostas educacionais, elaboradas pela tecnoburocracia central, através do processo de discussão das mesmas junto às equipes técnicas das instâncias administrativas hierarquicamente inferiores. (NEVES et al, 1984, p. 61)

[...] o papel que esses conselhos [Nacional, Estaduais e Municipais de Educação] desempenham não corresponde aos princípios de democratização e participação da comunidade nas decisões e no controle das políticas públicas, que os fundamentam. Pelo contrário, estes conselhos têm-se caracterizado pelo reforço dos grupos no poder, e por uma extrema burocratização. (DALL'IGNA, GOULARTE e MARTINS, 1996, p. 1)

A avaliação voltada apenas para os produtos educacionais - expressos no desempenho dos alunos em testes padronizados - se contrapõe à avaliação de processos, restringindo o papel do Estado a controlador dos resultados educacionais. Retirar a responsabilidade do governo pelo processo educacional faz parte das reformas educacionais de cunho neoliberal, nas quais mediante a descentralização (ou desconcentração), a gestão administrativa e financeira passam para a escola, tornando-a responsável pelo fracasso ou sucesso escolar. (SOUSA et al, 2000, p. 3)

Como pôde ser observado nas últimas citações, no final dos anos de 1990 detecta-se um aparente paradoxo entre centralização e descentralização: aparente porque em geral questiona-se o que vem sendo chamado pelo Estado de descentralização, que corresponderia a uma redistribuição de poder, de verbas e de responsabilidades entre os níveis de governo, mas que, na prática, teria contemplado apenas a responsabilidade, mantendo sob o controle do governo federal os recursos, articulados aos sistemas de avaliação. 


\title{
O Estado brasileiro nas últimas décadas: contexto e discussão da produção acadêmica
}

O início do período abordado nesta pesquisa pode ser caracterizado, no aspecto político, como dos anos mais autoritários e duros do regime militar, com sua gradativa abertura ao final da década. Porém, Fausto (1999) ressalta que nesse controle eram distinguidos dois setores da sociedade: um, minoritário, organizado e adversário do regime, para o qual era dirigida a repressão, e outro, constituído pela grande massa da população, em geral embalado pela ilusão dos anos de prosperidade econômica9 .

Desde 1964, a Escola Superior de Guerra ESG e sua proposição de desenvolvimento para o país, tornam-se dominantes no cenário nacional, como pensamento oficial do Estado, no regime militar.

\begin{abstract}
A ESG se coloca como adjuvante do Estado Moderno, que tem como objetivo levar a cabo o planejamento - uma questão técnica e científica - capaz de promover aceleradamente o desenvolvimento econômico. A democracia é um termo que assume uma polivalência muito grande: Estado interventor, manutenção da propriedade privada e é, ao mesmo tempo, um sentimento que deve guiar os indivíduos em todas as esferas da vida cotidiana. [...] Trata-se de um processo de reeducação tanto do povo como das elites, na família, na religião, nos clubes esportivos, etc. [...] As reformas propostas são reformas não antagônicas, isto é, que não entrariam em choque com os interesses econômicos dos diferentes grupos. [...] Não há $[\ldots]$ um setor social que poderia ser claramente identificado como idealmente capaz de levar a cabo a legitimação dessa proposta a não ser os próprios estagiários da ESG. [...] Mas seria ingênuo supor que o Bem-Estar possa ser conquistado sem a Segurança. O mundo está dividido entre dois blocos antagônicos e, para o Brasil, não há saída fora do Ocidente. Não se trata de uma filiação automática aos interesses norte-americanos, mas de uma pressão para que aqui seja implantado um novo programa, capaz de acelerar o desenvolvimento. A crítica ao capital estrangeiro é acirrada na ESG, sua entrada exige um controle restrito, mas é a única forma de desenvolver o país. (DEBERT, 2004, p. 4)
\end{abstract}

${ }^{9}$ Nos primeiros anos da década de 1970 ocorre o chamado milagre brasileiro, em referência ao rápido crescimento da economia do país, que declina para uma grave crise e recessão, em meados dos anos de 1980. 
Análises sobre a evolução da agenda pública brasileira (FAGNANI, 1997; MELO, 2001; e DRAIBE, 1989) afirmam, em comum, que o período do regime militar foi de consolidação do Sistema de Proteção Social do país, coincidindo, em linhas gerais, com a fase de crescimento econômico e de avanço em infraestrutura, em grande parte financiados pelo capital estrangeiro e pelo modelo econômico adotado, de concentração de poder e de renda. Em meados da década de 1980 tem início a crise desse modelo, acompanhada da recessão econômica acima mencionada.

Em relação à Educação, não se deve ignorar a influência da Teoria do Capital Humano ${ }^{10}$ nas proposições políticas, associada às idéias desenvolvimentistas, nem as relações econômicas, políticas e técnicas com os Estados Unidos, que marcam as décadas de 1960 e 1970 no Brasil.

Neste sentido, a lei $n^{\circ} 5692 / 71$, que reforma o então ensino primário e secundário, transformando-o em $1^{\circ}$ e $2^{\circ}$ graus, e estabelece a obrigatoriedade do ensino profissionalizante no $2^{\circ}$ grau, está fortemente associada ao desenvolvimentismo e à preocupação com o desenvolvimento do país, relacionada ao processo de urbanização e industrialização, crescente, e às demandas por profissionalização, advindas de parte da população. (GONÇALVES e GONÇALVES, 2007, p.8-9)

Para Fiori, o período desenvolvimentista do país, caracterizado por uma forte influência autoritária,

[...] deixa uma herança de desorganização política entre os principais grupos de interesse; de baixo indice de participação e controle da população sobre o exercício da autoridade pública em todos os níveis; de baixo grau de institucionalização e de escassíssima experiência e flexibilidade, sobretudo das elites, para a aceitação dos conflitos e o exercício da convivência política entre os 24 estados que compõem a federação brasileira. Isso dá uma dimensão aproximada do que tem sido o desafio da construção das condições democráticas de governabilidade, simultaneamente à administração da crise econômica e o esboço coletivo do horizonte final dessa nova ruptura-transição pelo Brasil (FIORI, 1996, p. 147).

\footnotetext{
${ }^{10}$ Sua proposição foi coordenada por Theodore W. Schultz, em 1950, nos Estados Unidos, e visava explicar os fatores que ocasionavam os diferentes níveis de desenvolvimento socioeconômico entre os países. Um de seus principais argumentos é de que há uma relação direta entre qualificação, força de trabalho e crescimento econômico.
} 
Parte da discussão sobre a crise do Estado ${ }^{11}$ envolve seu Sistema de Proteção Social, e passa a ser maior a demanda por aumento e redirecionamento dos gastos nesse âmbito. De 1985 a 1988, há a tentativa de implementação de um amplo projeto de reorganização institucional e econômica, no qual a importância da questão social é ampliada e a reforma do Sistema de Proteção Social adquire centralidade (FAGNANI, 1997). Esse processo influi na definição dessa função do Estado, por meio da Constituição de 1988, na qual ocorrem avanços positivos quanto ao padrão de proteção social do país, sugerindo um adensamento do caráter redistributivista das políticas sociais e uma maior responsabilidade pública na sua regulação, produção e operação (DRAIBE, 1989).

Nesse contexto, a década de 1980 traz novos desafios à questão educacional, e a ênfase passa a ser a eficiência do funcionamento das instituições escolares e a qualidade de seus resultados, não mais na perspectiva desenvolvimentista e tecnoburocrática, predominante dos anos de 1970. Essas questões são progressivamente incorporadas nos artigos analisados. É importante ressaltar a influência de organizações internacionais no estabelecimento dessas diretrizes, fixadas para o aparelho de Estado como um todo. Essa tendência permanece e se fortalece na década de 1990.

Quanto à Constituição de 1988, algumas das expectativas a ela colocadas já foram abordadas, mas podem ser observadas em uma citação bastante ilustrativa, que sintetiza as demandas presentes nos trabalhos, não só dessa década, mas de todo o período, por meio de princípios gerais.

[...] sugerimos alguns eixos básicos nos quais devem basear-se os dispositivos educacionais da nova Constituição.

1. Ensino público e gratuito em todos os níveis [...].

2. Qualidade do ensino [...].

3. Democratização das instituições [...].

4. Autonomia das instituições [...].

5. Laicidade do ensino [...].

${ }^{11}$ Essa crise envolve várias facetas e reúne sob o mesmo título diversas crises simultâneas: a) a fiscal, entendida como o excesso de gasto público social; b) a econômica, visando a um Estado regulador, indutor, coordenador e mobilizador dos agentes econômicos e sociais; c) a social, com a crise do Estado de Bem-Estar Social; d) a política, questionando-se a incapacidade de institucionalizar a democracia e prover uma cidadania adequada; e) a crise do modelo burocrático de gestão pública, tendo em vista os elevados custos e a baixa qualidade dos serviços prestados pelo Estado. Nesse sentido, a crise do Estado pode ser entendida como uma crise estrutural, convergência de crises que, conjugadas, levam à discussão sobre o papel do Estado, sob diferentes ângulos. 


\section{Orçamento para a educação [...]. \\ 7. Contra a subvenção às escolas privadas [...].}

(PINHEIRO, 1986, p.49-50)

O quadro de crises simultâneas levou, na década de 1980, a situações de grande peso simbólico, enquanto catalizadoras de expectativas e esperanças da população, também presentes nos trabalhos: as Diretas Já, a eleição de Tancredo Neves e a Assembléia Nacional Constituinte. Esses elementos constituíram marcos, nos quais foram depositadas imensas e talvez exageradas esperanças, na medida em que estavam muito além do que efetivamente poderia ser feito, naquele contexto. Possivelmente, a maioria delas foi desfeita, de diversas maneiras, refletindo também nos campos econômico e social. As expectativas da população pareciam voltar-se, em síntese, para a solução dos problemas econômicos e sociais do país, mais do que dos problemas políticos, aparentemente menos imediatos, embora começasse a se desenvolver uma crescente percepção a respeito dessa relação ${ }^{12}$.

É interessante notar que na década de 1980 não há referências diretas sobre a crise do Estado, embora ela já estivesse se delineando, e os trabalhos, ao evidenciarem os problemas do Estado, pudessem estar contribuindo e alimentando essa discussão. Por sua vez, ainda quantitativamente tímidas são as menções ao Estado neoliberal, que começa a ser notado e criticado, e que está relacionado à discussão da crise. Mesmo que não intencionalmente, parece que as discussões, críticas e argumentos a respeito da ineficiência e omissão do Estado e de seu Sistema de Proteção Social tenham colaborado ou tenham sido utilizadas de maneira distorcida para justificar, no discurso oficial, a mudança do modelo estatal para um que primasse por mais eficiência, por meio da racionalização de seus gastos - o que aparecerá de forma mais evidente na década de 1990, com as diretrizes de reforma do Estado.

A Constituição Federal de 1988 trouxe conquistas na garantia de direitos, mas mesmo estes são questionados, principalmente devido à falta de clareza quanto aos recursos necessários à sua efetiva concretização. Dessa forma, as esperanças voltam-se para a LDB, que começa a ser discutida, e que passa a ser o novo foco dos trabalhos, nos anos de 1990.

12 Em que nível a participação popular nos grandes movimentos do período refletiu, porém, uma maior conscientização política, ou até que ponto foi influenciada pela mídia, não cabe aqui discutir, necessitando de estudo específico. 
Em especial na segunda metade dessa década, os questionamentos e referências devem ser compreendidos no contexto de reforma do Estado. No governo Fernando Henrique Cardoso são propostas reformas constitucionais administrativa, fiscal, previdenciária - e a eliminação de monopólios estatais; cria-se o Ministério da Administração Federal e Reforma do Estado do Brasil, responsável pela condução do processo de reestruturação do Estado.

Especificamente quanto ao caso brasileiro, Barreto $(1999$, p. 2) analisa a reconstrução do Estado a partir do Plano Diretor da Reforma do Aparelho do Estado (1995) e indica a conjugação de quatro processos interdependentes, a saber:

- a redefinição das funções do Estado, orientada para a redução de seu tamanho e, principalmente, de seu contingente de pessoal, mediante a adoção de programas de privatização, terceirização e 'publicização';

- $\quad$ a redução do grau de interferência do Estado, mediante adoção de programas de desregulação e realização de reformas econômicas orientadas pra o mercado, visando sobretudo à promoção da capacidade de competição internacional do país;

- o aumento da governança do Estado - aqui entendida como a capacidade de tornar efetivas as decisões do governo, ou seja, de implementar políticas públicas de forma eficiente e conjugada com a sociedade -, envolvendo o ajuste fiscal - redirecionado à recuperação da autonomia financeira do Estado -, e a implantação da administração pública gerencial e

- o aumento da governabilidade, que consiste no fortalecimento da capacidade política do governo de intermediar interesses, garantir legitimidade e governar (p.112).

Ainda, conforme o Plano Diretor, são estabelecidos quatro setores de atuação estatal $^{13}$. A Educação está situada como Serviço não-exclusivo do Estado, em que atuariam simultaneamente o Estado, o setor privado e o setor público não-estatal. O critério estabelecido como de êxito administrativo para o atendimento desse setor foi a garantia de maior agilidade, qualidade e eficiência no atendimento das demandas sociais; e o objetivo, em relação à reforma do Estado, era "superar a rigidez burocrática decorrente da aplicação de normas burocráticas; lograr maior autonomia e responsabilidade para os dirigentes desses serviços". (BARRETO, 1999, p.112)

${ }^{13}$ São eles: núcleo estratégico, atividades exclusivas do Estado, serviços nãoexclusivos do Estado e produção de bens para o mercado. 
Devido à prioridade que esse modelo de Estado imprime à questão econômica, as principais críticas que lhe são feitas referem-se às conseqüências, no campo social, das diretrizes que adota. Mais especificamente, as controvérsias voltam-se aos efeitos negativos sobre o Sistema de Proteção Social, em que a Educação está inserida, e que são bastante destacados nos artigos analisados.

Em dezembro de 1996 é aprovada a Lei de Diretrizes e Bases da Educação Nacional, após oito anos de tramitação. Há diversas posições e críticas a respeito dessa LDB, que permeiam os artigos estudados; porém, é necessário considerar o contexto histórico pelo qual o projeto de lei passou, desde o início das discussões: governos José Sarney, Fernando Collor de Mello, Itamar Franco, e Fernando Henrique Cardoso (quando foi aprovada) ${ }^{14}$.

Além disso, é preciso situá-la no contexto internacional, considerando as profundas mudanças e questionamentos estruturais que ocorrem, e a forma como atingiram o Brasil. A influência internacional na política brasileira pode ser ilustrada pela ação de dois órgãos internacionais: a Comissão Econômica para a América Latina e Caribe (Cepal) e o Banco Mundial. Zibas (1997) distingue duas vertentes de atuação: a do Banco Mundial, "que absolutiza o mercado como agente de regulação social, atribuindo ao Estado uma atuação compensatória apenas nos casos de extrema desigualdade", e a da Cepal, que "embora também proponha uma reestruturação do Estado, reserva a ele um papel mais central e ampliado como elemento compensatório das diferenças sociais" (p. 59). Há convergências em suas políticas, como a descentralização das políticas sociais e a preocupação em obter maior eficiência no gasto social. Tais relações também são percebidas e evidenciadas nos artigos analisados, como determinantes para o processo entendido como de desresponsabilização do Estado brasileiro quanto às políticas sociais, em especial a Educação; a LDB seria um dado concreto, nesse sentido, embora também sejam indicados avanços nessa Lei, nos trabalhos analisados.

\section{Considerações finais}

A fim de evitar a redundância com relação a temas já anteriormente destacados, e para melhor pontuar algumas constatações, são enumeradas abaixo observações consideradas importantes no âmbito deste trabalho, a partir da delimitação estabelecida:

${ }^{14}$ Tanuri (1998) discute a tramitação do Projeto de Lei oriundo da Câmara dos Deputados (n. 1258 de 1988) e do substitutivo Darcy Ribeiro, bem como suas implicações na versão final, aprovada em 1996. 
1) A compreensão sobre a função e o papel do Estado em relação à Educação pôde ser observada, bem como os rumos que foi tomando no decorrer do período pesquisado. A década de 1970 caracteriza-se como de denúncia, principalmente, da atuação do Estado sob diretrizes capitalistas, seguido de longe pela referência a seu perfil autoritário e centralizador; na de 1980, há predominância da referência à ineficiência e omissão do Estado, seguida por várias outras como ao capitalismo, ao neoliberalismo e aos problemas de planejamento; e na de 1990 há mais referências ao Estado neoliberal, e à sua ineficiência e omissão (agora entendidas como desresponsabilização), centralização de controle e poder, e descentralização de responsabilidades, além de seu processo de crise e reforma.

2) Uma suposição confirmada foi a de que o contexto que envolve as décadas acabou por dar o tom dos discursos presentes na produção acadêmica; ou seja, o contexto permitiu um viés comum de abordagem quanto ao tema. Acredita-se que o resgate desenvolvido sobre o período e os trabalhos selecionados contribuíram para essa percepção e para a compreensão mais ampla das relações existentes entre a história e a construção das interpretações sobre ela, no que diz respeito ao tema abordado. Considerando que a produção acadêmica identificada nas demais áreas foi insignificante, em relação à Educação $(78,2 \%)$, reconhece-se que a perspectiva dessa área determinou a tendência acima mencionada, porém também está presente nas demais, em especial na História e nas Ciências Sociais.

3) Em cada década analisada, e mais notadamente a partir da de 1980, observou-se um curto espaço de tempo entre as ocorrências políticas e econômicas e sua discussão nas publicações, relacionadas à Educação. Assim, uma das características que se pode indicar sobre a produção é sua atualidade. Se essa atualidade gera a positiva contribuição a respeito do debate sobre os problemas e rumos da Educação, por outro lado, pode significar também o embaçamento na visão dos autores a respeito deles, sem o distanciamento que permitisse maior objetividade no tratamento do tema. Essa questão exigiria um estudo e discussão específicos.

4) Foi identificada uma forte tendência à repetição de idéias. Alguns problemas são levantados, discutidos e abordados repetida e incansavelmente, com poucas diferenças ou lentos avanços em seu entendimento. Também, são recorrentes os "deveria" ou "deve" ser assim, acompanhados de princípios gerais, mas não de, ao menos, indicações ou proposições mais elaboradas sobre como alcançar aquele objetivo.

5) A compreensão e discussão a respeito do Estado brasileiro, nos trabalhos analisados, privilegiam as questões estruturais, internas e externas ao país, caracterizando uma abordagem teórica em especial, o materialismo histórico. 
Embora, como já foi dito, não tenha sido objeto deste trabalho identificar e analisar o referencial teórico e seu uso nos artigos, essa conclusão deriva da caracterização predominante do Estado nos artigos. Nesse sentido, são exceções os trabalhos que abordam a participação e a responsabilidade dos agentes sociais no processo de decisão e direcionamento das ações do Estado, ou mesmo que compreendem e discutem os conflitos internos a ele, como disputas de poder. Da mesma forma, poucos trabalhos discutem a cultura política brasileira como possível responsável por grande parte das escolhas, ou mesmo pela ineficiência e pelos problemas inerentes à máquina estatal do país, desde o sentido mais amplo, quando se referem ao neoliberalismo, em nível mundial, até o micro, como a gestão das escolas.

Sugere-se, assim, mais atenção a esses aspectos das relações entre Estado e Educação no Brasil, considerando-se que reconhecer e considerar a estrutura patrimonialista do Estado, historicamente estabelecida na cultura brasileira, como parte fundamental do problema, permitiria avançar na compreensão, na discussão e, talvez, na proposição de encaminhamentos para questões e problemas referentes à Educação no país.

\section{REFERÊNCIAS}

ARROYO, Miguel G. Administração da educação, poder e participação. Educação e Sociedade, Campinas, n. 2, p. 36-46, jan. 1979.

AZEVEDO, Janete M. L. A temática da qualidade e a política educacional no Brasil. Educação e Sociedade, Campinas, n. 49, p. 449-467, dez. 1994.

BARRETO, Maria I. As organizações sociais na reforma do Estado brasileiro. In: PEREIRA, Luiz C. B.; GRAU, Núria C. O público não-estatal na reforma do Estado. Rio de Janeiro: FGV, 1999. p. 115-155.

BOURDIEU, Pierre. Lições da aula. São Paulo: Ática, 1988.

. O poder simbólico. Lisboa: Difel, 1989.

. Razões práticas: sobre a teoria da ação. São Paulo: Papirus, 1996.

BRAUDEL, Fernand. Escritos sobre a história. São Paulo: Perspectiva, 1978.

CAMPOS, Maria M. M.; PATTO, Maria H. S.; MUCCI, Cristina. A creche e a préescola. Cadernos de Pesquisa, São Paulo, n. 39, p. 35-42, nov. 1981. 
CASTRO, Cláudio de M. et al. Financiamento e custos da educação: conclusões de uma pesquisa na América Latina. Pesquisa e Planejamento, Rio de Janeiro, n. 10, p. 147-178, abr. 1980.

CHARTIER, Roger. A história cultural: entre práticas e representações. Lisboa: Difel, 1988.

DALL'IGNA, Maria A.; GOULARTE, Glauce F.; MARTINS, Erenita R. Conselhos Municipais de Educação: participação para quê? In: ANPED, 19., 1996. Anais... 3 p., CD-ROM.

DRAIBE, Sônia M. O Welfare State no Brasil: características e perspectivas. In: ANPOCS. Ciências sociais hoje. São Paulo: Vértice/ANPOCS, 1989. p. 13-61.

FAGNANI, Eduardo. Política social e pactos conservadores no Brasil: 1964-92. Cadernos FUNDAP, São Paulo, n. 21, p. 59-102, 1997.

FAUSTO, Bóris. História do Brasil. 6. ed. São Paulo: EDUSP/ FDE, 1999.

FIORI, José L. Ajuste, transição e governabilidade: o enigma brasileiro. In: TAVARES, Maria C.; FIORI, José L. (Des)ajuste global e modernização conservadora. Rio de Janeiro: Paz e Terra, 1996. p. 127-193.

FLEURY, Fernando. Educação, competitividade e o papel do setor produtivo. In: ANPAD, 17., 1993. Anais... v. 3: Administração da Produção, p. 8-22. CD-ROM.

GANDINI, Raquel P. C. Industrialização e educação; educação hoje: mercadoria. Educação e Sociedade, Campinas, n.7, p. 133-139, set. 1980.

GONÇALVES, Nadia G. A relação Estado-Educação na produção acadêmica brasileira (1971-2000). Tese (Doutorado em Educação) - Universidade de São Paulo, São Paulo, 2003.

GONÇALVES, Nadia G.; GONÇALVES, Sandro A. Desenvolvimentismo e educação: discurso governamental e políticas paranaenses nas décadas de 1960 e 1970. In: CONGRESO IBEROAMERICANO DE HISTORIA DE LA EDUCACIÓN, Buenos Aires, 2007. Anais... Buenos Aires, 2007. 25 p. CD-ROM.

MARCELINO, Gileno F. Modernização administrativa na educação. RAP, Rio de Janeiro, 15 (ed. extra), p. 98-141, 1981.

MARTINS, Clélia A. Política educacional e estado no sistema capitalista. In: ANPED, 13., 1990. Anais... 12 p. CD-ROM. 
MELCHIOR, José C. A. A aplicação de recursos financeiros em educação. Cadernos de Pesquisa, São Paulo, n. 25, p. 5-15, ago. 1978.

MELO, Marcos André. As sete vidas da agenda pública brasileira. In: RICO, Elizabeth M. (Org.). Avaliação de políticas sociais: uma questão em debate. 3. ed. São Paulo: Cortez/Instituto de Estudos Especiais, 2001.

MINTO, César A.; MONTEIRO, Aída; CATANI, Afrânio M. A nação convocada: subsídios para a análise de um documento governamental. Educação e Sociedade, Campinas, n. 56, p. 558-562, dez. 1996.

NEVES, Lúcia M. W. et al. Estado e planejamento educacional no Brasil. Cadernos de Pesquisa, São Paulo, n. 51, p. 55-63, nov. 1984.

PERONI, Vera M. V. O Estado brasileiro e a política educacional dos anos 90. In: ANPED, 23., 2000. Anais... 7 p. CD-ROM.

PINHEIRO, Maria F. S. Educação, constituições e constituinte. Sociedade e Estado, Brasília, v. 1, n. 2, p. 29-53, jul. 1986.

RIBEIRO, Sérgio C. A educação e a inserção do Brasil na modernidade. Cadernos de Pesquisa, São Paulo, n. 84, p. 63-82, fev. 1993.

SOUSA, Sandra M. Z. L. et al. Avaliação educacional e gestão: iniciativas no âmbito do município e Estado de São Paulo. In: ANPED, 23., 2000. Anais... 4 p. CD-ROM.

TANURI, Leonor M. A nova LDB e a questão da administração educacional. In: SILVA, Carmem S. B.; MACHADO, Lourdes M. (Org.). Nova LDB: trajetória para a cidadania? São Paulo: Arte \& Ciência, 1998. p. 33-38.

ZIBAS, Dagmar M. L. Escola pública versus escola privada: o fim da história? Cadernos de Pesquisa, São Paulo, n. 100, p. 57-77, mar. 1997.

Texto recebido em 23 out. 2007

Texto aprovado em 12 dez. 2007 